\title{
The Effect of Pre-Harvest Application of Pectic Oligosaccharides and Abscisic Acid on Technological Ripening and Anthocyanin Profile of 'Syrah' Must and Grapes Grown in a Warm Climate
}

\author{
S.S. Sandoval-Silva, E. Aispuro-Hernández, C. Corrales-Maldonado, I. Vargas-Arispuro, M.A. Martínez-Téllez* \\ Centro de Investigación en Alimentación y Desarrollo, A.C. (CIAD, A.C.), Hermosillo, Sonora, México.
}

Submitted for publication: October 2020

Accepted for publication: March 2021

Key words: Abscisic acid, berry skin color, climate change, elicitor, pectic oligosaccharides, red wine grape quality, viticulture

\begin{abstract}
The progressive increase of environmental temperature as a consequence of climate change is a challenge for the wine industry. Elevated temperatures during grape ripening affect the development of grape skin color by inhibiting the synthesis of pigments and promoting their degradation, which causes an imbalance in the chromatic quality of must and red wine. The application of pectic oligosaccharides (POs) and abscisic acid (ABA) triggers the phenylpropanoid pathway and increases the color index in grapes. Since the atharvest pigments and phenolic compounds are determinant for wine quality, this work addressed the preharvest application of POs and ABA as an in-field strategy for improving the quality of Syrah must and grapes grown in a warm climate. The color development, physicochemical parameters, phenolic content, and pigments in berries and must were evaluated. Results showed POs and ABA improved berry color development and anthocyanin content during ripening. Musts from POs-treated berries exhibited the highest phenols concentration and the most intense color, related to higher chroma values and anthocyanin content, particularly delphinidin, petunidin, and malvidin 3-glucosides, while ABA improved must tonality by reducing the hue angle. In summary, POs and ABA application at veráison, differentially modulated the technological ripening of Syrah grapes and can be an alternative to conventional agrochemicals to preserve the quality of musts elaborated from grapes grown in warm climates, by increasing the content of phenolic compounds and enhancing berry skin color development through the differential accumulation of anthocyanins.
\end{abstract}

\begin{abstract}
INTRODUCTION
Global warming is currently an open challenge for the wine industry. Among the problems attributed to global warming are the decrease in color intensity in red wines and the increase in the alcohol content (Santos et al., 2020). Color alterations are related to the effect of high temperatures for either inhibiting the production of anthocyanins, the natural pigments of grapes, or triggering their degradation (Sadras \& Moran, 2012; Gouot et al., 2019). The progressive increment in global mean temperatures along with the predicted shifts in the minimum and maximum temperature values in the near future will probably compromise the balance between the appropriate maturity index (in terms of berry sweetness and acidity) and optimal grape skin color and aroma-related compounds at harvest (Santos et al., 2020). A delay in the harvest period due to lack of optimal berry coloration causes a loss of volatile compounds and organic acids, and increases
\end{abstract}

the accumulation of sugars; the higher the content of fermentable sugars, the higher the alcohol produced during the fermentation process. Alcohol levels above 14.5 degrees make difficult to perceive certain aromas and flavors (Goldner et al., 2009). On the other hand, early harvest may affect both the acidity perception, due to a higher concentration of organic acids, and the accumulation of secondary metabolites such as phenolic and aromatic components, resulting in a wine with a pronounced unpleasant character related to an excessive sour taste (Longo et al., 2018; Zhao et al., 2019). Since such effects critically influence the composition of grapes, the production of balanced high-quality wines is compromised, which highlights the need to search for alternatives that prevent the drop in the quality of grapes and their respective wines when produced under the forthcoming unfavorable climate conditions for viticulture.

\footnotetext{
*Corresponding author: M.A. Martínez-Téllez, CIAD, A.C., Carretera Gustavo Enrique Astiazarán Rosas, \#46, Col. La Victoria, 83304, Hermosillo,Sonora,México.E-mail: norawa@ciad.mx

S.S. Sandoval-Silva and E. Aispuro-Hernández contributed equally to the manuscript

Acknowledgements: Thanks to Francisco Soto-Cordova and Olivia Briceño for technical assistance. S.S.S-S. thanks to the Mexican National Council for Science and Technology (CONACYT) for his graduate scholarship. Our special gratitude to Ing. Francisco Salazar Giottonini for allowing the trial to be conducted in his vineyard at Hacienda San Jerónimo
} 
A number of chemical substances, have demonstrated to effectively mimic the action of plant defense-related signaling molecules to stimulate the plant's secondary metabolism, thereby eliciting the synthesis of phenolic compounds during the ripening of grape berries and modulating the accumulation and profile of chemical constituents associated with the sensorial attributes of berries and wines, including anthocyanins, tannins, and flavonols (Ruiz-García et al., 2013; Gómez-Plaza et al., 2017).

Abscisic acid (ABA) is a phytohormone implicated in a diversity of relevant physiological processes in various plant organs. For over a decade, the application of ABA has shown a positive impact in the color attributes of table grapes (Lurie et al., 2009; Crupi et al., 2019; Shahab et al., 2020) and more recently in Plavac Mali wine grapes (Mucalo et al., 2020). ABA increases in the skin of grape berries the expression of the UDP-glucose:flavonoid 3-O-glucosyltransferase (UFGT) gene. The UFGT enzyme catalyzes the final step of anthocyanin biosynthesis (Koyama et al., 2018). Also, the exogenous application of ABA has effectively increased the skin content of relevant phenolic compounds such as proanthocyanidins in Monastrell wine grapes (RuizGarcía et al., 2013). However, most of the studies on the application of elicitors to improve the chromatic quality of grapes and wines have been conducted in regions with temperate climates, in which the impact of the lack of grape berry quality is less pronounced than in hot climate regions because when temperatures rise to $35^{\circ} \mathrm{C}$, the accumulation of flavonoids in grapes decreases (Gouot et al., 2019), and anthocyanin biosynthesis is inhibited, thus affecting berry skin coloration (Kliewer \& Torres, 1972). Besides, the technological use of ABA as a plant growth regulator has shown some limitations including its high cost (Crupi et al., 2019). Therefore, new strategies to avoid the loss of quality of grapes for winemaking are still required.

Among the current worth studying technologies to ameliorate the lack of grape berry coloration, the application of biological elicitors stands as a safe and eco-friendly alternative that presents advantages in comparison to the adverse effects triggered by chemically-synthetized plant growth regulators that can cause defoliation, premature aging, and berry softening (Leão et al., 2015; Pessenti et al., 2019). Some biologically active pectin-derived oligosaccharides are known to induce biochemical and physiological responses in plants (Ferrari et al., 2013). In Vitis vinifera, the exogenous application of pectic oligosaccharides (POs) induces the expression of defensive markers in grapevine leaves (Ferrari et al., 2013). In Flame Seedless red table grapes preharvest POs application has been shown to enhance berry skin anthocyanin accumulation and color due to stimulation of phenylalanine ammonia-lyase (PAL) gene expression in an ethylene-independent manner (Ochoa-Villarreal et al., 2011). PAL is a key regulatory enzyme of the phenylpropanoid pathway, in which several metabolites related to grape color quality and flavor are synthetized. Therefore, we hypothesize that the pre-harvest application of POs will improve the berry color attributes with higher accumulation of anthocyanin pigments in grape berries of the blue-blackskinned $V$. vinifera L. cv. Syrah, thus allowing the production of balanced musts for winemaking. The aim of the work was to evaluate the effect of the pre-harvest application of POs on the maturation, anthocyanin profile, content of polyphenols and chromatic quality of Syrah grapes and musts produced in a warm climate region.

\section{MATERIALS AND METHODS}

\section{Preparation of pectic oligosaccharides and abscisic acid}

The POs with degree of polymerization in the range of 2 to 20 were obtained and characterized according to VeraGuzmán et al. (2017). Briefly, commercial pectin (Danisco Mexicana) was dissolved in water (1:45) and adjusted to $\mathrm{pH}$ 5. Then, it was hydrolyzed with a pectinase from Aspergillus niger (Sigma, USA) at $23^{\circ} \mathrm{C}$ for $3 \mathrm{~h}$, stopping the reaction by autoclaving. The solution was dried using a Yamato ADL311S spray dryer to obtain the powdered mixture of POs. The degree of polymerization was determined by anion exchange chromatography with an amperometric pulse detector (HPAEC-PAD) (Dionex, Sunnyvale, CA) and a PD10 column. The $\mathrm{S}$-abscisic acid (ABA; ProTone ${ }^{\circledR} \mathrm{SG}$ ) was purchased from Valent BioSciences Corp. (USA) and used as a control growth regulator substance as demonstrated in previous studies on table grapes (Peppi et al., 2008; Yamamoto et al., 2015).

\section{Vegetal material and experimental}

The experiments were carried out during the 2018 productive season in 15-year old vines (Vitis vinifera L. cv. Syrah) grafted to Freedom rootstocks imported from California, USA. Grapevines were grown in an organic vineyard located in Guadalupe de Ures, Sonora (latitude $29^{\circ} 23^{\prime} 56.1^{\prime \prime} \mathrm{N}$, longitude $110^{\circ} 28^{\prime} 06.7^{\prime} \mathrm{W}$ ) and arranged with a spacing of $2.5 \mathrm{~m} \times 1.5 \mathrm{~m}$ and trained in a bilateral cordon system. The area is characterized by a semi-arid climate with a minimum and maximum average temperature of $21.7^{\circ} \mathrm{C}$ and $40.4^{\circ} \mathrm{C}$ during the experimental period, and an annual rainfall of about $430 \mathrm{~mm}$. Eighteen plants with a similar fruit load (approximately 60 bunches per plant) were selected and randomly assigned to three different groups. Treatments consisted of a direct spraying of either water (controls), 1500 ppm POs (effective concentration according to OchoaVillarreal et al. (2011) and Villegas et al. (2016)) or 120 ppm ABA (recommended concentration by the provider), at 0 and $48 \mathrm{~h}$ after the onset of veráison. All solutions contained $0.1 \%$ glycerol as surfactant.

Four clusters per treatment were collected at 0,5,10, and 15 days post-treatments, while the remaining load of treated clusters was harvested at day 20, when control berries had reached a mean technological maturity of $20^{\circ}$ Brix. There were four replications per treatment and the experiment was conducted twice, in which each collected bunch was considered a biological replicate. At harvest (day 20 after treatment application), the fruit load from each group of grapevines was divided into four batches for must preparation by direct maceration of grapes at room temperature, and each batch was considered a replicate (three treatments $\mathrm{x}$ four batches each).

\section{Reference analyses}

The different response parameters evaluated during grape berries maturation were color index, total phenols, and 
anthocyanins concentration on berry skin, while total soluble solids, $\mathrm{pH}$, and titratable acidity were assessed in the pulp. The color attributes (brightness, chroma, and tone angle), probable alcohol percentage, total phenols, and anthocyanins were evaluated in the must.

The color parameters were determined based on the CIELab color space system with a Minolta CR-300 colorimeter (Konica Minolta,Tokyo, Japan) and a $\mathrm{D}_{65}$ light source to measure the $\mathrm{L}^{*}$ (lightness), $\mathrm{a}^{*}$ (red), and $\mathrm{b}^{*}$ (yellow) coordinates and to calculate the chroma value (C) and hue angle. To monitor berry skin color development during grape maturation the color index for red grapes (CIRG) was calculated on 30 berries per sampled cluster according to the technique described by Carreño et al. (1995) with the following formula:

$C I R G=\frac{\left(180-{ }^{\circ} \text { hue }\right)}{\left(L^{*}+C\right)}$

The colorimeter was equipped with a glass lightprojection tube CR-A33f to measure the color parameters of musts on $10 \mathrm{~mL}-$ low refractive borosilicate glass vials.

The content of total soluble solids (TSS) was determined following the methodology from Moreno \& Oyola (2016) using a digital refractometer Atago PAL-1 calibrated with distilled water and recording the results in ${ }^{\circ}$ Brix. The percentage of probable alcohol (\% PA) was estimated from the must's TSS content according to the formula proposed by Bakker \& Clarke (2011a) as follows:

$\% P A=\frac{T S S}{1.8}$

The titratable acidity (TA) was calculated following the methodology proposed by the OIV (2019) using a METTLER DL21 automatic titrator, titrating up to a $\mathrm{pH}$ of 8 with $0.1 \mathrm{~N}$ $\mathrm{NaOH}$; the results were expressed as g of tartaric acid / L. The grape berry maturity index (MI) was determined as the ratio between TSS and TA contents.

Berry skin phenols were extracted with $80 \%$ methanol following the Singleton \& Rossi method (1965) with modifications. Briefly, $1.5 \mathrm{~g}$ of epicarp tissue were homogenized with an Ultra-Turrax T25, sonicated $30 \mathrm{~min}$ in a Branson 1520 water bath and centrifuged at 23,400 x g for $15 \mathrm{~min}$ at $4^{\circ} \mathrm{C}$. The pellet was re-extracted until complete discoloration. Three $\mathrm{mL}$ of distilled $\mathrm{H}_{2} \mathrm{O}$ and $250 \mu \mathrm{L}$ of Folin-Ciocalteu $1 \mathrm{~N}$ reagent were added to $50 \mu \mathrm{L}$ of either berry skin methanolic extracts or musts, allowing them to rest for $5 \mathrm{~min}$. Subsequently, $750 \mu \mathrm{L}$ of $20 \% \mathrm{Na}_{2} \mathrm{CO}_{3}$ and 950 $\mu \mathrm{L}$ of distilled $\mathrm{H}_{2} \mathrm{O}$ were added, allowed to stand for $30 \mathrm{~min}$, and then spectrophotometric readings were done at $765 \mathrm{~nm}$. A gallic acid calibration curve was performed to calculate the content of total phenols; the results were expressed as $\mathrm{mg}$ of gallic acid equivalents (GAE) per $100 \mathrm{~g}$ of either fresh skin tissue (for grapes) or must.

The concentration of individual anthocyanins in musts and berries was determined with a high-resolution liquid chromatography (HPLC) system (Agilent Technologies 1260 infinity, Santa Clara, CA, USA) equipped with a diode array detector and a Nucleosil 120 C18 column (4 x $250 \mathrm{~mm}$ with a particle size of $5 \mu \mathrm{m}$; Cronus). Grape epicarp (1 g) was ground with liquid nitrogen and homogenized with methanol-HCl 1\% (v/v) for anthocyanins extraction (OchoaVillarreal et al., 2011). The HPLC mobile phase consisted of $10 \%$ formic acid (A) and acetonitrile (B), with a gradient of: 5 to $9 \% \mathrm{~B}, 5 \mathrm{~min} ; 9$ to $11 \%$ of $\mathrm{B}, 10 \mathrm{~min} ; 11$ to $15 \%$ of B, $15 \mathrm{~min} ; 15$ to $20 \%$ of B, $25 \mathrm{~min}$; and 20 to $30 \%$ of $\mathrm{B}, 30 \mathrm{~min}$. The flow rate was $1 \mathrm{~mL} / \mathrm{min}$, with a detection wavelength of $520 \mathrm{~nm}$. Anthocyanin concentrations were calculated from standard curves made with commercial 3-O-monoglycosylated anthocyanins (delphinidin, cyanidin, petunidin, peonidin, and malvidin 3-glucosides) purchased from Polyphenols Laboratories (Norway), and were expressed as $\mu \mathrm{g}$ per gram of either fresh skin tissue (for grapes) or must. The sum of the individual anthocyanins was considered as the total mono-glycosylated anthocyanin content.

\section{Statistical analysis}

The effect of the treatments was evaluated using a completely randomized one-way experimental design. An analysis of variance was carried out at a significance level of $p<0.05$, and a comparison of means with Tukey's multiple range test at $p<0.05$ using the statistical package NCSS version 12 (NCSS, LLC, Kaysville, UT, USA).

\section{RESULTS}

The application of POs and ABA influences the technological maturity of Syrah grapes during berry ripening

POs and ABA differentially influenced the parameters of quality with respect to control berries. A periodic decrease in berry skin luminosity along with a marked shift in hue/ tone starting from yellowish-green to red and then dark violet occurred during the ripening of 'Syrah' grapes, which is reflected in the CIRG values that were progressively increasing (Fig. 1). Initial CIRG values at veráison averaged $1.21 \pm 0.47$ and reached $6.69 \pm 1.03$ at harvest. From day 10 onwards, significant differences were observed between controls and treated berries, in which ABA treatment induced the highest CIRG on days $15(7.22 \pm 0.81)$ and $20(8.19 \pm$ 0.22). On harvest day, CIRG values of POs and ABA treated berries were significantly higher than controls.

The $\mathrm{pH}$ of Syrah grape berries was not altered by any treatment and showed a slow increase during ripening, with an all-treatment average of $3.28 \pm 0.17$ at the start of veráison to $4.19 \pm 0.15$ at harvest. A typical progressive TA decrease and TSS increase occurred during the Syrah grape ripening process (Fig. 2). At harvest, TSS concentrations ranged from 19.52 to $21.59 \%$, with no differences among treatments. However, POs-treated grapes reached significantly higher ${ }^{\circ}$ Brix values than controls and ABA-treated grapes at days 10 and 15 post-application (Fig. 2A), trend observed for all the sampling dates. Figure 2B shows the behavior of TA during grape ripening, in which significant $(\mathrm{p}<0.05)$ lower values were observed by day 10 for POs-treated grapes, while at harvest (day 20), all the experimental groups shared similar acidity around $4 \mathrm{~g}$ of tartaric acid/L.

The TSS/TA ratio was used as a maturity indicator 


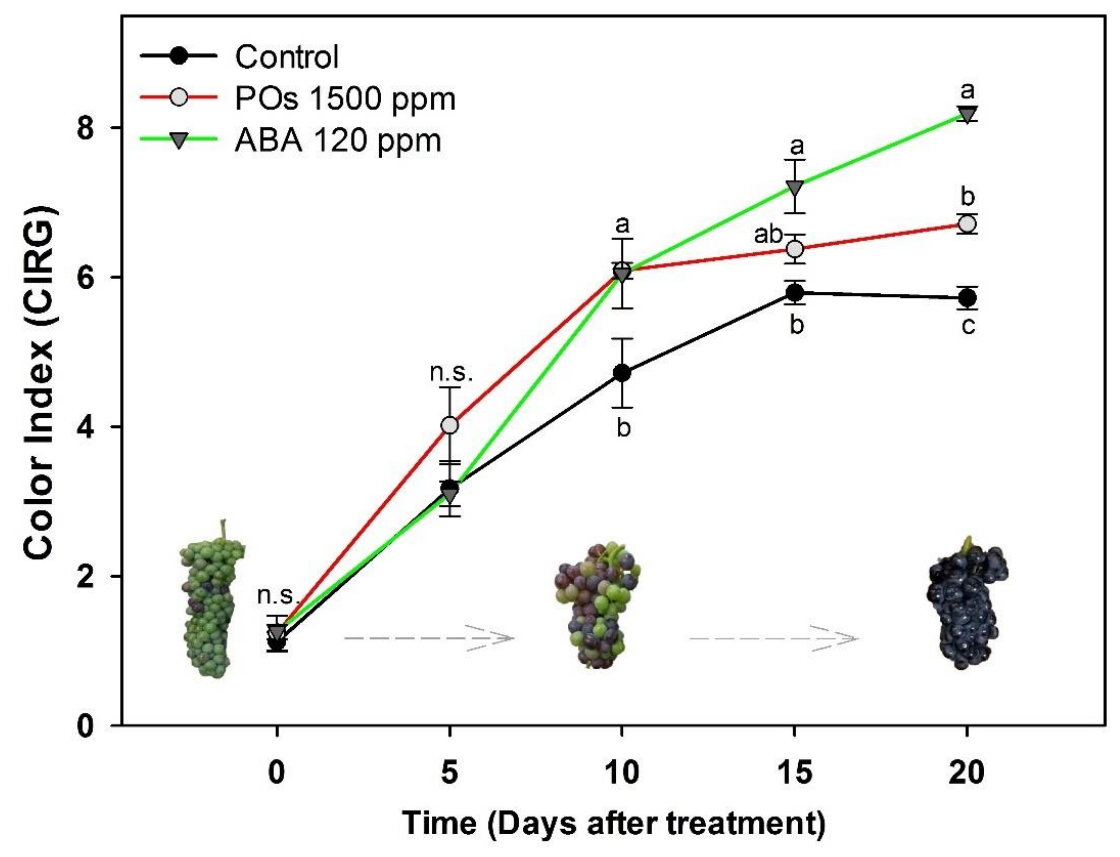

FIGURE 1

Color development in red wine grapes cv. Syrah treated at véraison with pectic oligosaccharides (POs) or S-abscisic acid $(A B A)$. The mean values \pm SE of two experiments $(n=8)$ are presented. Different literals indicate significant differences at $p<$ 0.05 and no significant differences are indicated as n.s.

during grape berry ripening. The MI showed a gradual increase that reached the maximum values at day 20 for all the experimental groups (Fig. 2C). A significantly higher MI was promoted by the effect of POs treatment in days 10 and 15 post-application, as a result of the increased TSS and reduced TA. By harvest day, all treatments had reached a similar maturity.

The POs and ABA treatments promote the accumulation of anthocyanins in the skin of Syrah grapes, but with a different distribution pattern.

The total mono-glycosylated anthocyanin content showed an increasing trend during grape berry ripening (Fig. 3). POs induced earlier anthocyanins accumulation with significant higher levels than the rest of the groups by day five after treatments. The peak values for control- and POs-treated grapes occurred on day 15, while ABA-treated berries showed their highest anthocyanins content at harvest (day 20), which was greater than the rest of the treatments. The individual mono-glycosylated anthocyanin profile varied among sampling dates and treatments. Malvidin 3-glucoside was consistently the most abundant anthocyanin, followed by delphinidin, peonidin, petunidin, and cyanidin 3-glucosides.

By day 10 post-application the contents of petunidin, peonidin, and malvidin 3-glucosides were significantly lower in control berries than either of the treatment groups, while delphinidin and cyanidin were only higher in ABA- and POs-treated grapes, respectively. On day 15, anthocyanin levels were similar in all the experimental groups, except for the higher content of malvidin 3-glucoside in ABA-treated grapes. On harvest day, peonidin and malvidin 3-glucosides were increased by both ABA and POs treatments, while delphinidin and petunidin 3-glucosides contents were higher only in ABA-treated grape berries.

The mean content of total phenolic compounds in the skin of Syrah grape berries ranged from $1474 \pm 66 \mathrm{mg}$ $\mathrm{GAE} / 100 \mathrm{~g} \mathrm{FW}$ at veráison to $1203 \pm 140$ at harvest. Control berries showed a decreasing tendency during the first 10 days posttreatment. No clear tendency was observed on POstreated berries, while relative steady levels were observed in ABA-treated grapes through the maturation period, reaching a significant higher concentration than the controls at days 10 and 20 (Fig. 4).

The application of POs and $A B A$ at véraison differentially affects the color, contents of anthocyanins and total phenols, and probable alcohol yield in musts

The effect of the treatments on colorimetric and enological characteristics of musts is shown in Table 1. The color-related attributes chroma and ${ }^{\circ}$ hue were differentially influenced by the treatments, while luminosity $\left(\mathrm{L}^{*}\right)$ remained unaffected. Must from POs-treated berries showed a significant higher chroma value than controls, while ABA reduced $2.25^{\circ}$ the hue angle of must in relation to the untreated control. While the titratable acidity was not affected by any treatment, POs significantly increased the content of total phenols in must with $35 \%$ and $27 \%$ higher levels than those prepared from control and ABA-treated berries, respectively.

The probable alcohol content (Table 1) was calculated from both grapes sampled at day 15 after treatments application and musts prepared with grapes at harvest. The results suggest that the pre-harvest application of POs would have significantly increased the alcoholic percentage of wines prepared with grapes harvested both at days 15 and 
20, compared to control and ABA-treated berries, probably due to a faster accumulation of berry sugar.

Figure 5 shows the effect of the treatments on the individual content of anthocyanins-3-glucosides in Syrah musts. Musts prepared from POs-treated berries reached a higher level of three different anthocyanins: malvidin, petunidin, and delphinidin 3-glucosides, which may be related to the increased color intensity with respect to control musts. No statistical differences were observed in the

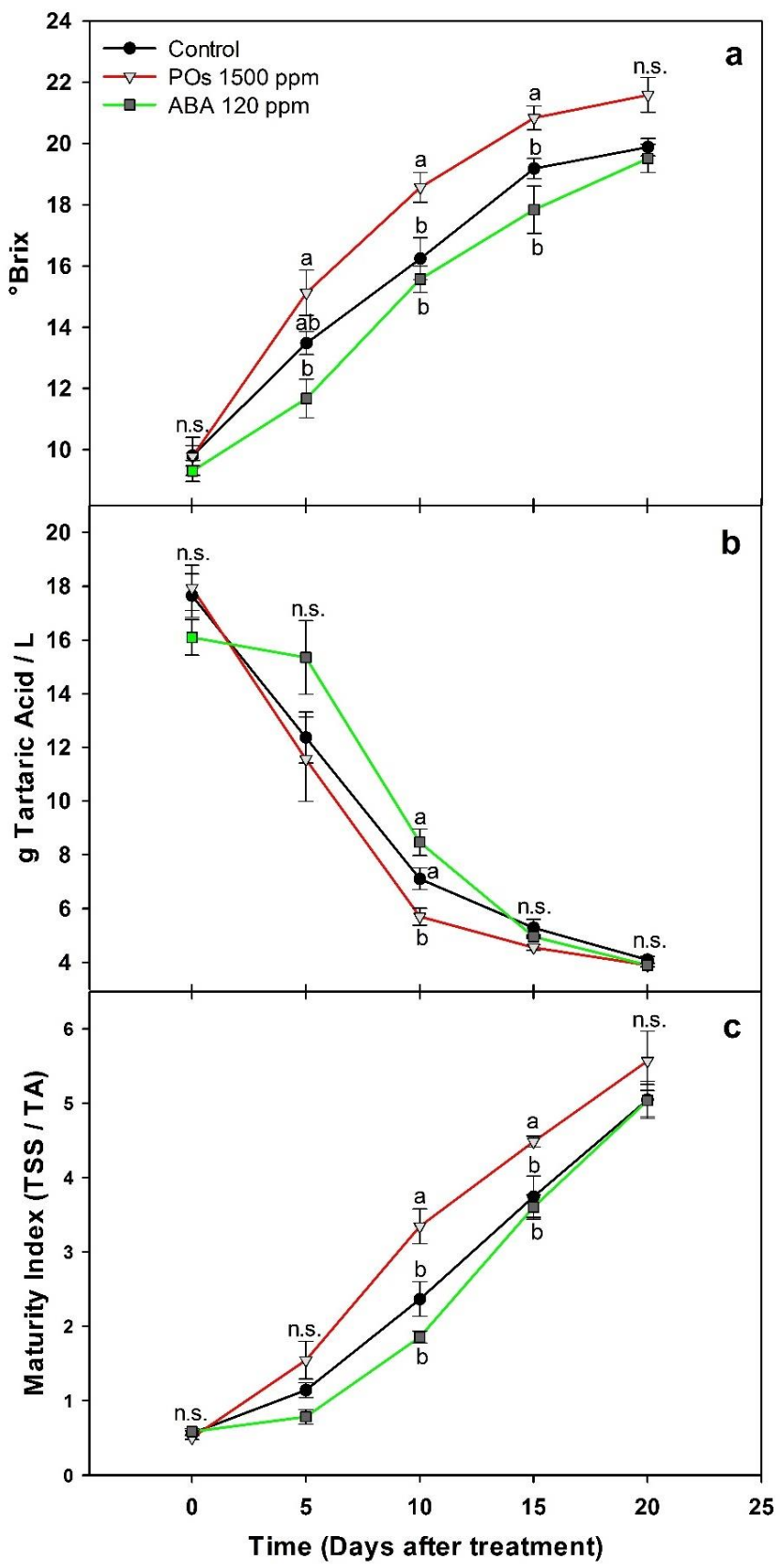

FIGURE 2

Maturity parameters during ripening of Syrah grape berries treated at véraison with pectic oligosaccharides (POs) or S-abscisic acid (ABA). Total soluble solids content (a); titratable acidity (b); maturity index (c). The mean values \pm SE of two experiments $(n=8)$ are presented. Different literals indicate significant differences at $p<0.05$ and no significant differences are indicated as n.s. concentration of anthocyanins in must prepared form ABAtreated berries.

\section{DISCUSSION}

The pre-harvest application of POs and ABA differentially influenced important quality-related parameters both during berry ripening and in musts. The color attributes were among the most influenced parameters by effect of the treatments in terms of the CIRG index for grapes and ${ }^{\circ}$ hue and chroma values for must, even when the harvest occurred until control berries reached $20^{\circ}$ Brix. The mean at-harvest CIRG values observed for Syrah grapes in this work are in the range of the reported for red-black and blue-black cultivars such as Cabernet Sauvignon, Dolcetto, Freisa, and Plassa (Rolle \& Guidoni, 2007). CIRG value variations may reflect nonobvious differences in berry skin color intensity and tonality allowing differentiating among red wine grape varieties. Since the berry skin color positively correlates to the concentration of anthocyanins in the skin of colored grape cultivars (Rolle \& Guidoni, 2007), the significantly higher CIRG values observed in ABA- and POs-treated berries suggest an increased accumulation of these pigments. These findings agree with higher CIRG values and total anthocyanin contents found in the skin of ABA- and POs-treated red table grapes (Ochoa-Villarreal et al., 2011; Shahab et al., 2019).

Regarding the chromatic quality of the obtained musts, a higher chroma indicates a more saturated color or higher intensity, while hue indicates the tonality in a scale of $360^{\circ}$; the closer to $0^{\circ}$ the hue angle is, the redder the color. The shifts in ${ }^{\circ}$ hue may result from different pigments profiles or due to $\mathrm{pH}$ variations (Heredia et al., 1998; Torskangerpoll \& Andersen, 2005), however, in this case $\mathrm{pH}$ was not affected by the treatments, suggesting that the decreased ${ }^{\circ}$ hue in must prepared from ABA-treated berries is related to a differential phenolics composition rather than a $\mathrm{pH}$-associated effect. Also, the increased chroma in must prepared from POstreated berries suggests higher concentrations of anthocyanic pigments and/or other polyphenols abundant in grape seeds and skin that are released during maceration and are related to color stabilization. Released phenolic compounds are chemically modified to different extents during winemaking and aging, which determines the final wine color and taste (Smith et al., 2015). The chemical changes that most influence wine organoleptic and sensorial attributes include modifications in the complexity of tannins and copigmentation, the latter being a spontaneous phenomenon characterized by chemical associations between pigments and non-colored components further leading to the formation of complex anthocyanin-derived pigments that greatly impact the color of the wine (Malaj et al., 2013; Escribano-Bailón et al., 2019; Laitila \& Salminen, 2020). Thus, the effects in the must chromatic quality observed in the present work may also be the result of bathochromic and hyperchromic shifts caused by the formation of oligomeric pigments either by self-association of free anthocyanins or by their association with organic or metallic copigments after maceration (Escribano-Bailón et al., 2019; Laitila \& Salminen, 2020).

Typically, during fruit ripening the content of organic acids decreases while the accumulation of sugars increases, therefore, TA and TSS are flavor-related quality parameters 


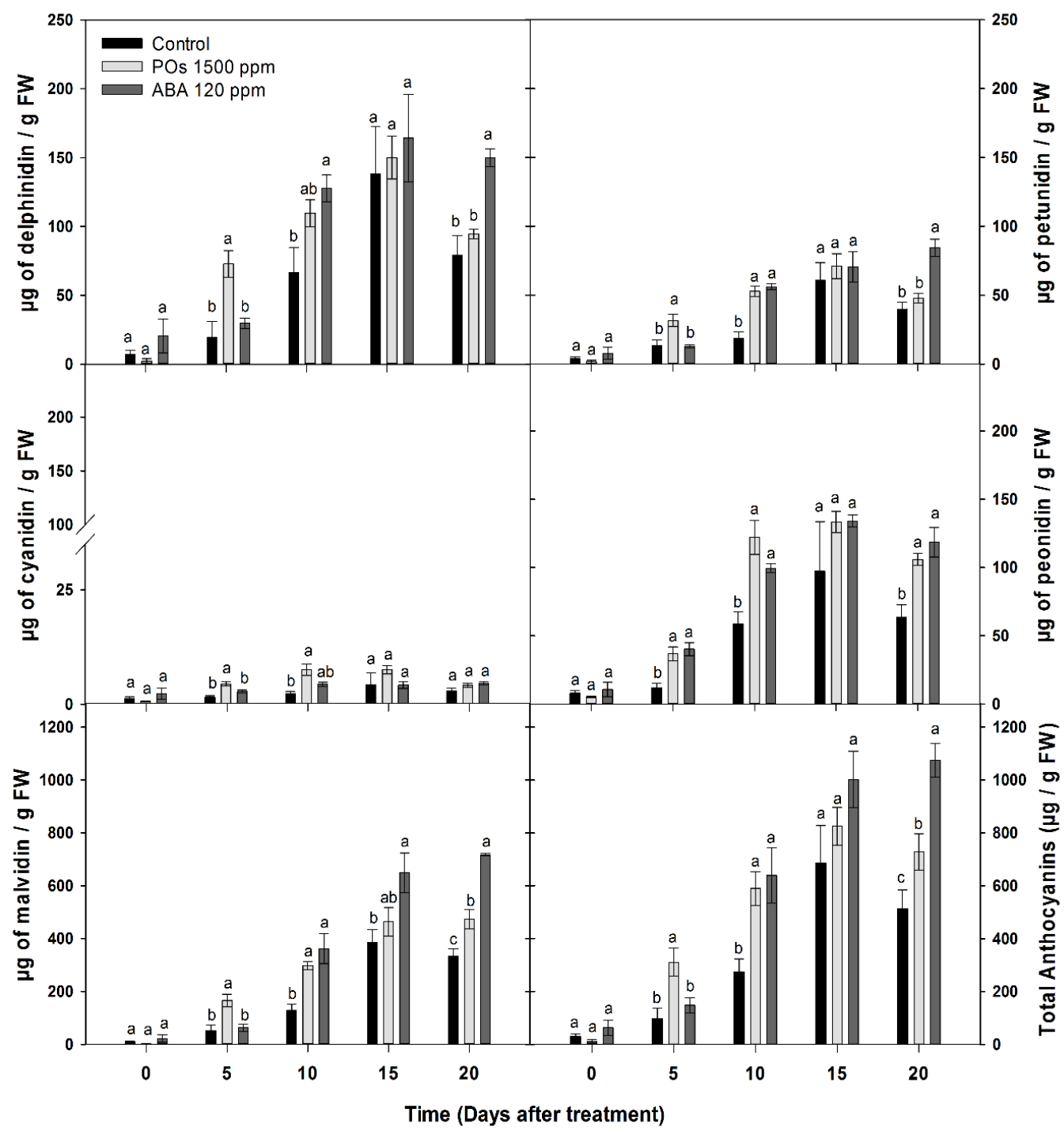

FIGURE 3

Berry skin anthocyanin profile during ripening of Syrah grapes treated at véraison with pectic oligosaccharides (POs) or S-abscisic acid (ABA). Bars represent the mean values $\pm \mathrm{SE}(\mathrm{n}=4)$. Different literals indicate significant differences at $\mathrm{p}<0.05$.

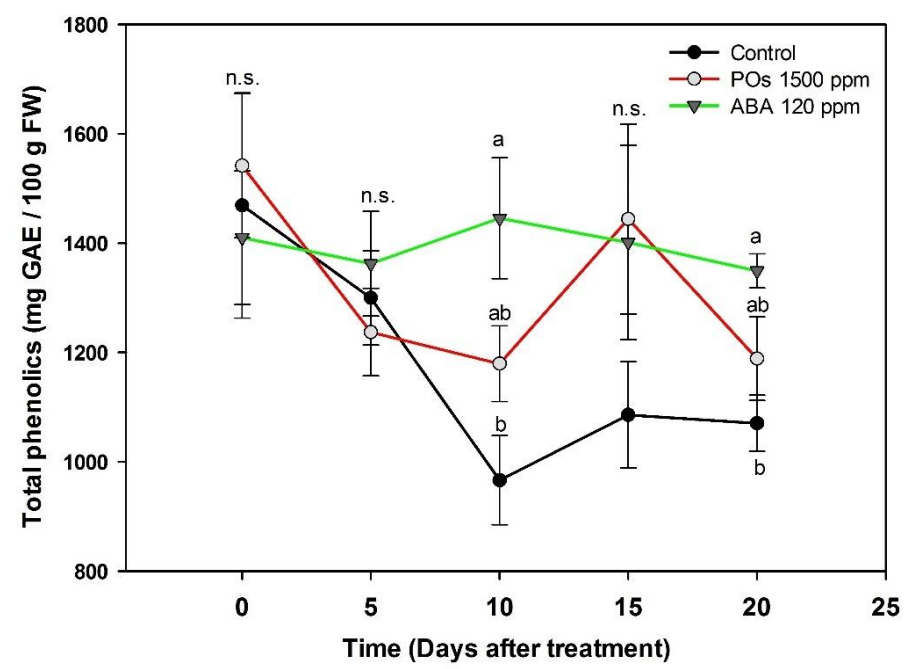

FIGURE 4

Total phenolic content during ripening of Syrah grape berries treated at véraison with pectic oligosaccharides (POs) or S-abscisic acid $(A B A)$. The mean values \pm SE of two experiments $(n=8)$ are presented. Different literals indicate significant differences at $\mathrm{p}<0.05$ and no significant differences are indicated as n.s. 


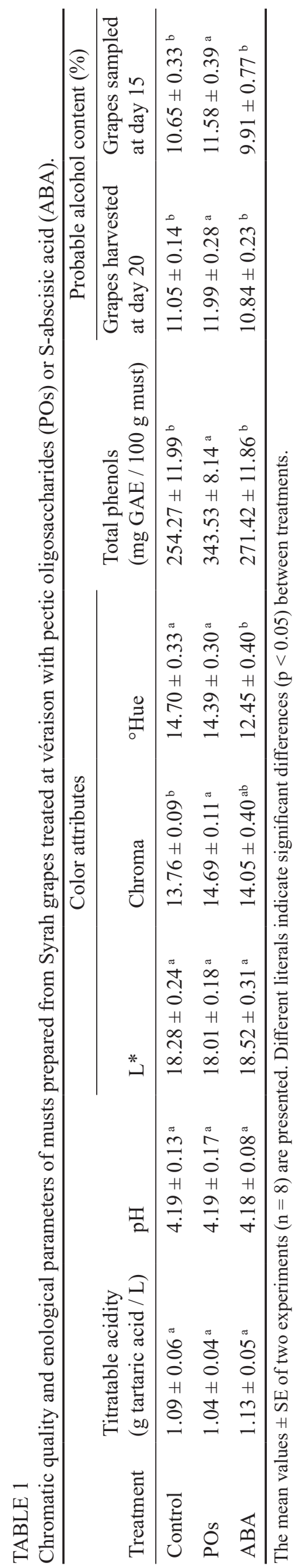

commonly used to monitor the maturity of grapes. It has been proposed that a higher sugar accumulation correlates with an increased anthocyanin accumulation in red wine grapes (Pérez-Magariño \& González-San José, 2006), suggesting it may have implications beyond flavor and sweetness, influencing the berry color quality as well. For wine grapes, the recommended sugar content at harvest is between 20.5 and $23.5^{\circ}$ Brix (van Schalkwyk \& Archer, 2000). Particularly, for the cv. Syrah it has been suggested that an ideal grape technological maturity as related to higher content of pleasant aroma volatiles, phenolics and color of wines is reached at $21^{\circ}$ Brix in tropical regions (Barbará et al., 2019). Interestingly, when Syrah grape harvest occurs at $19{ }^{\circ}$ Brix, an increased number of volatiles related to pleasant aromas such as some esters, alcohols, and terpenes are detected in the resulting young wines; however, high maceration time may lead to excessive astringency and bitterness, which are related to the high levels of tannin monomers characteristic of berries with lower ripeness degree (Aith Barbará et al., 2020) and to an increased extraction of seed proanthocyanidins (or polymeric tannins) (Smith et al., 2015). On the other hand, the at-harvest TA values reported for mature Syrah grapes vary between 2.7 and $5.2 \mathrm{~g} / \mathrm{L}$ according to the growing region, season, and time to harvest (Giacosa et al., 2015; Canoura et al., 2018; Carlomagno et al., 2018), which agrees with our observations for grapes grown in a semi-arid warm climate.

Grapes grown in warm climates commonly develop a suboptimal berry skin color, which makes it difficult to achieve a proper balance of those attributes important for a good quality red wine in terms of color and flavor. In this work, POs-treated berries was the only experimental group to reach the recommended sugar content umbral of $20.5^{\circ}$ Brix by day 15 , but the skin color index continued to increase until harvest and titratable acids remained practically steady thereafter. On the contrary, control berries reached its highest skin color development at day 15, with no further increase by harvest time. So far, these findings demonstrate POs treatment influenced the ripening of Syrah grapes, suggesting it may contribute to reduce the time to harvest up to five days.

The content and balance of organic acids and phenolic compounds is critical for the organoleptic quality of wines. The mean at-harvest total phenolics content in Syrah grapes was similar to those found in the dark blue-colored wine grapes cvs. Blaufränkisch and Merlot grown in temperate climate (Pavić et al., 2019), suggesting the adaptability of $V$. vinifera to maintain adequate levels of these relevant compounds even under suboptimal climate conditions. The preharvest application of elicitors to increase the content of phenolic compounds in grapes has shown contrasting results related to the species, cultivar, type of elicitor, and vintage (Sandhu et al., 2011; Ruiz-García et al., 2013; Gómez-Plaza et al., 2017). While methyl jasmonate, benzothiadiazole, and ABA were all able to increase the content of anthocyanins in both $V$. vinifera and $V$. rotundifolia grapes, the effect of these elicitors on the content of flavonols and proanthocyanidins has been more controversial. On the one hand, ABA and methyl jasmonate treatments increased the content of flavonols in muscadine and Syrah grapes, but not in the cvs. 


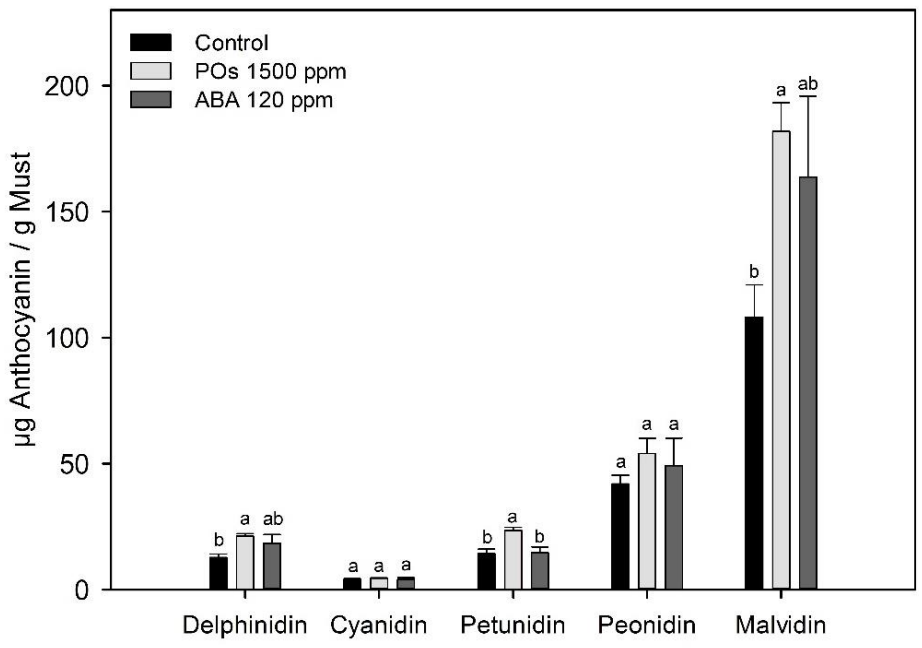

FIGURE 5

Content of anthocyanins in musts prepared from Syrah grapes treated at véraison with pectic oligosaccharides (POs) or S-abscisic acid $(A B A)$. Bars represent the mean values $\pm \operatorname{SE}(n=4)$. Different literals indicate significant differences at $p<0.05$.

Monastrell and Merlot (Sandhu et al., 2011; Gómez-Plaza et al., 2017). On the other hand, ABA application increased the content of grape skin tannins in Monastrell berries, whereas benzothiadiazole and methyl jasmonate treatments had not a significant effect in the same cultivar (Ruiz-García et al., 2013), however, in grapes of the cv. Merlot, methyl jasmonate treatment did increase the content of tannins (Gómez-Plaza et al., 2017).

The importance of the phenolic compounds content lies in their copigmentation capacity, by which they stabilize the anthocyanins in solution resulting in enhanced color (Malaj et al., 2013). Various authors have addressed the relevance of copigmentation with phenolic compounds by adding enological tannins or phenolic extracts during pre- and postfermentative periods, obtaining young red wines with a better colorimetric quality and stability (Álvarez et al., 2009; Gordillo et al., 2014; Bimpilas et al., 2016). Therefore, it would be expected that treatments capable of increasing the phenolic content of grapes would produce red wines with improved chromatic characteristics. However, Ruiz-García et al. (2013) found that wines elaborated with Monastrell grapes that had been treated with ABA to increase the skin content of anthocyanins and tannins showed no differences in color intensity, total phenolics content, and antioxidant activity than wines prepared from control berries with lower content of phenolic compounds. In comparison, wines elaborated with methyl jasmonate- and benzothiadioazoletreated berries showed enhanced color and higher content of total phenols (Ruiz-García et al., 2013), which highlights the importance of studying the specific effect of the different plant elicitors on the profile and extractability of grape phenolics and the final quality of the wine. These findings partially support our results, in which musts prepared with ABA-treated berries had a lower content of total phenolic compounds than those prepared with POs-treated berries and suggest that the increased chroma found in must prepared with POs-treated berries may likely be related to the increased content of phenolic compounds after berry maceration, which consequently favors anthocyanins copigmentation and must color.

Our findings suggest POs-treated berries achieved a more balanced technological maturity by increasing the color and TSS during ripening of Syrah grapes, suggesting POs treatment would allow harvest to be conducted from day 15 onwards. During fermentation, most of the sugars in the must will be transformed into alcohol, leaving the rest responsible for the sweet taste of the final product. Also, breakdown products of the residual sugars may contribute to the aroma of mature wine (Bakker \& Clarke, 2011b). It is estimated that for every $18 \mathrm{~g}$ of sugar / $\mathrm{L}$ in the must, the alcoholic content of the wine will increase by $1 \%$, approximately (Bakker \& Clarke, 2011a). Hence, the probable alcohol levels promoted by POs-treatment would allow wines prepared from grapes harvested on days 15 and 20 after treatment application to fall within the low-alcohol category (10.0 to $12.0 \%$ range) that favors the perception of the organoleptic properties of wines, especially sweet and fruity aromas (Goldner et al., 2009). However, the present work did not evaluate the impact of POs-applications on the accumulation of aroma-related compounds and aroma precursors. Therefore, our results may open the gate for future studies to evaluate the effect of these treatments on the content and profile of aroma-related volatiles and the overall organoleptic attributes of wine.

The berry skin anthocyanin accumulation and profile were modulated during Syrah grape ripening by effect of the treatments. Both inducers promoted a differential accumulation of anthocyanins. ABA increased the content of delphinidin and petunidin 3-glucosides, which confer purple and blue-reddish tonalities to plant tissues (Rolle \& Guidoni, 2007; Khoo et al., 2017), thus favoring an augmented purplish pigmentation. POs mainly enhanced the red saturation by promoting higher at-harvest levels than controls of peonidin and malvidin 3-glucosides, pigments respectively related to red and purplish-red tonalities at the vacuolar $\mathrm{pH}$ (Heredia et al., 1998). Anthocyanins biosynthesis is transcriptionally regulated by members of the MYB family of transcription 
factors (Villegas et al., 2016; Koyama et al., 2018). Exogenous ABA induced the expression of $M y b A 1$ and $M y b A 2$ genes in red table grapes (Koyama et al., 2018) and POs application increased $M y b A 1$ and $M y b 5 A$ expression levels and temporarily reduced $M y b 4 A$ transcript levels in Cabernet Sauvignon grapes (Villegas et al., 2016). This differential regulation of MYB transcription factors may in part explain the particular modulation of the anthocyanin profile exerted by POs and ABA treatments.

On the other hand, Syrah must prepared from POstreated berries showed an increased concentration of malvidin, petunidin, and delphinidin 3-glucosides, which are molecules three-substituted in the B ring and are localized in the area of the red-purple hues, while peonidin and cyanidin are localized in the red-orange area (Heredia et al., 1998; Rolle \& Guidoni, 2007). Particularly, malvidin and petunidin 3-glucosides are methylated anthocyanins, the former being the major pigment in young red wines and contributing precursors for the formation of more complex pigments responsible for the characteristic darker dusty red tonality in mature wines; petunidin provides intense purplish-red colors and delphinidin blue-violet tones (Khoo et al., 2017). It is worth noting that although anthocyanin-3-glucosides are the predominating anthocyanin molecular species in this cultivar, with approximately $57 \%$ of the total anthocyanic pigments, Syrah grapes contain varying amounts of acylated anthocyanins and are particularly rich in malvidin 3-p-coumarylglucoside and malvidin 3-acetylglucoside, which represent up to $22 \%$ and $9 \%$ of the total anthocyanins, respectively (Mazza, 1995). Therefore, future studies should evaluate the effect of these inducers on the pattern of acylated anthocyanins.

\section{CONCLUSION}

This work addressed the utilization of pectic oligosaccharides and abscisic acid as an in-field strategy for improving the quality of berries and musts in warm semi-arid climates by respectively promoting an enhanced skin color development and a more intense must color, which is concomitant to a higher and differential accumulation of anthocyanin pigments and total phenolic compounds during ripening of Syrah grapes. It is worth noting, however, that the pigments present in the must can undergo chemical transformations during the different stages of winemaking, leading to the formation of more complex condensation products with varying chromatic characteristics that depend on the content, profile, and availability of organic and metallic precursors, which altogether determine the final color and organoleptic attributes of the wine. Therefore, it would be necessary to evaluate if the color improvement observed in the grapes and musts from the present work will also be reflected after fermentation and wine aging stages.

\section{LITERATURE CITED}

Aith Barbará, J., Primieri Nicolli, K., Souza-Silva, É.A., Camarão Telles Biasoto, A., Welke, J.E. \& Alcaraz Zini, C., 2020. Volatile profile and aroma potential of tropical Syrah wines elaborated in different maturation and maceration times using comprehensive two-dimensional gas chromatography and olfactometry. Food Chem. 308, 125552.
Álvarez, I., Aleixandre, J.L., García, M.J., Lizama, V. \& AleixandreTudó, J.L., 2009. Effect of the prefermentative addition of copigments on the polyphenolic composition of Tempranillo wines after malolactic fermentation. Eur. Food Res. Technol. 228(4), 501-510.

Bakker, J. \& Clarke, R.J., 2011a. Basic taste and stimulant components. In: Wine flavour chemistry. Wiley-Blackwell, Oxford, UK. pp. 89-154.

Bakker, J. \& Clarke, R.J., 2011b. Sherry, port and madeira. In: Wine flavour chemistry. Wiley-Blackwell, Oxford, UK. pp. 291-339.

Barbará, J.A., Silva, É.A.S., Biasoto, A.C.T., Gomes, A.A., Correa, L.C., Leão, P.C.S. \& Zini, C.A., 2019. Maturation and maceration effects on tropical red wines assessed by chromatography and analysis of variance principal component analysis. J. Braz. Chem. Soc. 30(7), 1357-1377.

Bimpilas, A., Panagopoulou, M., Tsimogiannis, D. \& Oreopoulou, V., 2016. Anthocyanin copigmentation and color of wine: The effect of naturally obtained hydroxycinnamic acids as cofactors. Food Chem. 197, 39-46.

Canoura, C., Kelly, M.T. \& Ojeda, H., 2018. Effect of irrigation and timing and type of nitrogen application on the biochemical composition of Vitis vinifera L. cv. Chardonnay and Syrah grapeberries. Food Chem. 241, 171181.

Carlomagno, A., Novello, V., Ferrandino, A., Genre, A., Lovisolo, C. \& Hunter, J.J., 2018. Pre-harvest berry shrinkage in cv 'Shiraz' (Vitis vinifera L.): Understanding sap flow by means of tracing. Sci. Hortic. 233, 394-406.

Carreño, J., Martínez, A., Almela, L. \& Fernández-López, J.A., 1995. Proposal of an index for the objective evaluation of the colour of red table grapes. Food Res. Int. 28(4), 373-377.

Crupi, P., Alba, V., Masi, G., Caputo, A.R. \& Tarricone, L., 2019. Effect of two exogenous plant growth regulators on the color and quality parameters of seedless table grape berries. Food Res. Int. 126, 108667.

Escribano-Bailón, M.T., Rivas-Gonzalo, J.C. \& García-Estévez, I., 2019. Wine color evolution and stability. In: Red wine technology. Academic Press, London, UK. pp. 195-205.

Ferrari, S., Savatin, D.V., Sicilia, F., Gramegna, G., Cervone, F. \& Lorenzo, G.D., 2013. Oligogalacturonides: plant damage-associated molecular patterns and regulators of growth and development. Front. Plant Sci. 4, 49.

Giacosa, S., Marengo, F., Guidoni, S., Rolle, L. \& Hunter, J.J., 2015. Anthocyanin yield and skin softening during maceration, as affected by vineyard row orientation and grape ripeness of Vitis vinifera L. cv. Shiraz. Food Chem. 174, 8-15.

Goldner, M.C., Zamora, M.C., Lira, P.D.L., Gianninoto, H. \& Bandoni, A., 2009. Effect of ethanol level in the perception of aroma attributes and the detection of volatile compounds in red wine. J. Sens. Stud. 24(2), 243-257.

Gómez-Plaza, E., Bautista-Ortín, A.B., Ruiz-García, Y., FernándezFernández, J.I. \& Gil-Muñoz, R., 2017. Effect of elicitors on the evolution of grape phenolic compounds during the ripening period. J. Sci. Food Agric. 97(3), 977-983.

Gordillo, B., Cejudo-Bastante, M.J., Rodríguez-Pulido, F.J., Jara-Palacios, M.J., Ramírez-Pérez, P., González-Miret, M.L. \& Heredia, F.J., 2014. Impact of adding white pomace to red grapes on the phenolic composition and color stability of syrah wines from a warm climate. J. Agric. Food Chem. 62(12), 2663-2671.

Gouot, J.C., Smith, J.P., Holzapfel, B.P. \& Barril, C., 2019. Grape berry flavonoid responses to high bunch temperatures post véraison: Effect of intensity and duration of exposure. Molecules 24(23), 4341.

Heredia, F.J., Francia-Aricha, E.M., Rivas-Gonzalo, J.C., Vicario, I.M. \& Santos-Buelga, C., 1998. Chromatic characterization of anthocyanins from red grapes - I. pH effect. Food Chem. 63(4), 491-498.

Khoo, H.E., Azlan, A., Tang, S.T. \& Lim, S.M., 2017. Anthocyanidins and anthocyanins: Colored pigments as food, pharmaceutical ingredients, and the potential health benefits. Food Nutr. Res. 61(1), 1361779 
Kliewer, W.M. \& Torres, R.E., 1972. Effect of controlled day and night temperatures on grape coloration. Am. J. Enol. Vitic. 23(2), 71-77.

Koyama, R., Roberto, S.R., de Souza, R.T., Borges, W.F.S., Anderson, M., Waterhouse, A.L., Cantu, D., Fidelibus, M.W. \& Blanco-Ulate, B., 2018. Exogenous abscisic acid promotes anthocyanin biosynthesis and increased expression of flavonoid synthesis genes in Vitis vinifera $\times$ Vitis labrusca table grapes in a subtropical region. Front. Plant Sci. 9, 323

Laitila, J.E. \& Salminen, J.-P., 2020. Relevance of the concentrations and sizes of oligomeric red wine pigments to the color intensity of commercial red wines. J. Agric. Food Chem. 68(11), 3576-3584.

Leão, P.C.S., Lima, M.A.C., Costa, J.P.D. \& da Trindade, D.C.G., 2015. Abscisic acid and ethephon for improving red color and quality of crimson seedless grapes grown in a tropical region. Am. J. Enol. Vitic. 66(1), 37-45.

Longo, R., Blackman, J.W., Antalick, G., Torley, P.J., Rogiers, S.Y. \& Schmidtke, L.M., 2018. A comparative study of partial dealcoholisation versus early harvest: Effects on wine volatile and sensory profiles. Food Chem. 261, 21-29.

Lurie, S., Ovadia, R., Nissim-Levi, A., Oren-Shamir, M., Kaplunov, T., Zutahy, Y., Weksler, H. \& Lichter, A., 2009. Abscisic acid improves colour development in "Crimson Seedless" grapes in the vineyard and on detached berries. J. Hortic. Sci. Biotechnol. 84(6), 639-644.

Malaj, N., Simone, B.C.D., Quartarolo, A.D. \& Russo, N., 2013. Spectrophotometric study of the copigmentation of malvidin 3-O-glucoside with p-coumaric, vanillic and syringic acids. Food Chem. 141(4), 3614 3620 .

Mazza, G., 1995. Anthocyanins in grapes and grape products. Crit. Rev. Food Sci. Nutr. 35(4), 341-371.

Moreno, B.L. \& Oyola, Y.A.D., 2016. Caracterización de parámetros fisicoquímicos en frutos de mora (Rubus alpinus Macfad). Acta Agron. $65(2), 130-136$.

Mucalo, A., Maletić, E. \& Zdunić, G., 2020. Extended harvest date alter flavonoid composition and chromatic characteristics of plavac mali (Vitis vinifera L.) grape berries. Foods 9(9), 1155.

Ochoa-Villarreal, M., Vargas-Arispuro, I., Islas-Osuna, M.A., GonzálezAguilar, G. \& Martínez-Téllez, M.Á., 2011. Pectin-derived oligosaccharides increase color and anthocyanin content in Flame Seedless grapes. J. Sci. Food Agric. 91(10), 1928-1930.

OIV - Compendium of International Methods of Analysis of Wines and Musts (2 vol.) 2019. Online: http://www.oiv.int/en/technical-standards-anddocuments/methods-of-analysis/compendium-of-international-methods-ofanalysis-of-wines-and-musts-2-vol [accessed 14 October 2020].

Pavić, V., Kujundžić, T., Kopić, M., Jukić, V., Braun, U., Schwander, F. \& Drenjančević, M., 2019. Effects of defoliation on phenolic concentrations, antioxidant and antibacterial activity of grape skin extracts of the varieties Blaufränkisch and Merlot (Vitis vinifera L.). Molecules 24(13), 2444.

Peppi, M.C., Walker, M.A. \& Fidelibus, M.W., 2008. Application of abscisic acid rapidly upregulated UFGT gene expression and improved color of grape berries. Vitis 47(1), 11-14.

Pérez-Magariño, S. \& González-San José, M.L., 2006. Polyphenols and colour variability of red wines made from grapes harvested at different ripeness grade. Food Chem. 96(2), 197-208.

Pessenti, I.L., Ayub, R.A. \& Botelho, R.V., 2019. Defoliation, application of S-ABA and vegetal extracts on the quality of grape and wine Malbec cultivar. Rev. Bras. Frutic. 41(3), e-018.
Rolle, L. \& Guidoni, S., 2007. Color and anthocyanin evaluation of red winegrapes by CIE L*, a*, b* parameters. J. Int. des Sci. la Vigne du Vin 41(4), 193-201.

Ruiz-García, Y., Gil-Muñoz, R., López-Roca, J.M., Martínez-Cutillas, A., Romero-Cascales, I. \& Gómez-Plaza, E., 2013. Increasing the phenolic compound content of grapes by preharvest application of abcisic acid and a combination of methyl jasmonate and benzothiadiazole. J. Agric. Food Chem. 61(16), 3978-3983.

Sadras, V.O. \& Moran, M.A., 2012. Elevated temperature decouples anthocyanins and sugars in berries of Shiraz and Cabernet Franc. Aust. J. Grape Wine Res. 18(2), 115-122.

Sandhu, A.K., Gray, D.J., Lu, J. \& Gu, L., 2011. Effects of exogenous abscisic acid on antioxidant capacities, anthocyanins, and flavonol contents of muscadine grape (Vitis rotundifolia) skins. Food Chem. 126(3), 982-988.

Santos, J.A., Fraga, H., Malheiro, A.C., Moutinho-Pereira, J., Dinis, L.-T., Correia, C., Moriondo, M., Leolini, L., Dibari, C., Costafreda-Aumedes, S., Kartschall, T., Menz, C., Molitor, D., Junk, J., Beyer, M. \& Schultz, H.R., 2020. A review of the potential climate change impacts and adaptation options for european viticulture. Appl. Sci. 10(9), 3092.

van Schalkwyk, H. \& Archer, E., 2000. Optimum ripeness in wine grapes WinelLand. Online: https://www.wineland.co.za/optimum-ripeness-inwine-grapes/ [accessed 18 February 2021].

Shahab, M., Roberto, S.R., Ahmed, S., Colombo, R.C., Silvestre, J.P., Koyama, R. \& de Souza, R.T., 2020. Relationship between anthocyanins and skin color of table grapes treated with abscisic acid at different stages of berry ripening. Sci. Hortic. 259, 108859 .

Singleton, V.L. \& Rossi, J.A., 1965. Colorimetry of total phenolics with phosphomolybdic-phosphotungstic acid reagents. Am. J. Enol. Vitic. 16(3), 144-158.

Smith, P.A., McRae, J.M. \& Bindon, K.A., 2015. Impact of winemaking practices on the concentration and composition of tannins in red wine. Aust. J. Grape Wine Res. 21(S1), 601-614.

Torskangerpoll, K. \& Andersen, Ø.M., 2005. Colour stability of anthocyanins in aqueous solutions at various $\mathrm{pH}$ values. Food Chem. 89(3), 427-440.

Vera-Guzman, A.M., Lafuente, M.T., Aispuro-Hernandez, E., VargasArispuro, I. \& Martinez-Tellez, M.A., 2017. Pectic and galacturonic acid oligosaccharides on the postharvest performance of citrus fruits. HortScience 52(2), 264-270.

Villegas, D., Handford, M., Alcalde, J.A. \& Perez-Donoso, A., 2016. Exogenous application of pectin-derived oligosaccharides to grape berries modifies anthocyanin accumulation, composition and gene expression. Plant Physiol. Biochem. 104, 125-133.

Yamamoto, L.Y., de Assis, A.M., Roberto, S.R., Bovolenta, Y.R., Nixdorf, S.L., García-Romero, E., Gómez-Alonso, S. \& Hermosín-Gutiérrez, I., 2015. Application of abscisic acid (S-ABA) to cv. Isabel grapes (Vitis vinifera $\times$ Vitis labrusca) for color improvement: Effects on color, phenolic composition and antioxidant capacity of their grape juice. Food Res. Int. $77,572-583$.

Zhao, T., Wu, J., Meng, J., Shi, P., Fang, Y., Zhang, Z. \& Sun, X., 2019. Harvesting at the right time: Maturity and its effects on the aromatic characteristics of cabernet sauvignon wine. Molecules 24(15), 2777. 